\title{
Partial Hydatidiform Mole
}

National Cancer Institute

\section{Source}

National Cancer Institute. Partial Hydatidiform Mole. NCI Thesaurus. Code C4293.

A gestational trophoblastic disorder characterized by the presence of an abnormal fetus and two populations of chorionic villi: one population which is unremarkable and a second one which shows hydropic changes. 